\title{
THE ECOLOGY OF XENOPHYOPHORES, AN ENIGMATIC GROUP OF AGGLUTINATING RHIZOPODS
}

\author{
LEVIN, Lisa A., Scripps Institution of Oceanography, Univ. of California, San \\ Diego, La Jolla, CA 92093-0227.
}

Xenophyophores are large, agglutinating protozoans whose modern distribution is limited exclusively to the deep sea ( $>500 \mathrm{~m}$ water depth). Test morphologies vary from simple discoidal forms to elaborately folded or reticulated forms. Often specific particle sizes or minerals are selected for test construction. Tests are typically $1-5 \mathrm{~cm}$ in diameter, but some species may be up to $25 \mathrm{~cm}$ in longest dimension. Xenophyophores have been reported from a wide variety of soft- and hard-substrate deep-sea settings, including foram sands, calcareous and hemipelagic oozes, manganese nodule beds, fresh basalts, and hydrothermal oxides. They appear to obtain highest densities (often $>1 / \mathrm{m}^{2}$ ) on sloped substrates such as occur on seamounts, continental slopes, canyons, and trenches. Most xenophyophores live as epifauna on the sea floor and feed by actively or passively capturing suspended particles, but several species live as infauna and are presumed to be deposit feeders. It has been proposed that xenophyophores may garden bacteria within tests to provide an additional food source. Xenophyophores are distinguished from foraminifera by the occurrence of: (1) protoplasm encased within an organic membrane, (2) barite crystals within the protoplasm, and (3) tightly packed strands of fecal pellets (stercomare) within an organic membrane in the test.

Xenophyophore tests and surrounding sediments are known to be hotspots of metazoan activity in a variety of settings. Tests provide habitat and presumably refuge for many invertebrate groups, and sediments beneath epifaunal xenophyophore tests often exhibit elevated densities of macrofauna and meiofauna. Radiochemical studies suggest that xenophyophore tests are sites of enhanced particle flux to the seabed. Associated metazoans may be taking advantage of elevated food supplies in the vicinity of tests, or may be passively trapped by xenophyophore tests during dispersal stages.

Xenophyophores are not known from the fossil record. A resemblance between the infaunal xenophyophore Occultammina profunda and the trace fossil Paleodictyon has been noted by Swinbanks. Similar structures have been observed on the mid Atlantic ridge, but their identification as xenophyophores has not been confirmed. Maybury and Evans report a strong resemblance in external morphology, fine structure and barite content between modern xenophyophores in the genus Psammina and some Carboniferous phylloid algae, but fall short of suggesting a systematic relationship. Broader knowledge of xenophyophore morphology and ecology among ichnologists may lead to discovery of possible fossil antecedents. In addition, confirmation of xenophyophore presence could provide valuable information concerning paleohabitats. 